\title{
A Noção de Experiência na História da Sexualidade: implicações políticas e formativas
}

Santiago Pich'

'Universidade Federal de Santa Catarina (UFSC), Florianópolis/SC - Brasil

RESUMO - A Noção de Experiência na História da Sexualidade: implicações políticas e formativas. $\mathrm{O}$ artigo trata do problema da experiência no terceiro domínio da obra de Michel Foucault, tomando como principal fonte os três primeiros volumes da História da sexualidade. Nele, analisa-se o lugar da experiência como uma categoria estruturante da obra e do pensar do intelectual francês, mostrando o caráter constitutivamente político dessa elaboração e os desdobramentos possíveis para pensar a formação humana. A experiência é concebida como um modo de relação consigo que implica a transformação de si a partir de uma lenta elaboração artesanal da própria existência, que se dá sempre na relação com o Outro, o que possibilita conceber a formação humana a partir da constituição ética-estéticapolítica do sujeito nessa relação.

Palavras-chave: Experiência. Política. Ética. Formação Humana. Michel Foucault.

ABSTRACT - The Notion of Experience in the History of Sexuality: political and educational implications. This essay deals with the problem of experience in the third period of Michel Foucault's work, taking as its main source the first three volumes of the History of Sexuality. It analyses the place of experience as a structuring category of the work, and of the French intellectual's thinking, showing the constitutively political character of this elaboration and possible developments to conceive human education. Experience is conceived as a way of relating to oneself that implies the transformation of oneself, based on a slow artisanal elaboration of one's own existence, based on the relationship with the Other, which makes it possible to conceive human education from the ethical-aesthetic-political constitution of the subject in this relationship.

Keywords: Experience. Politics. Ethics. Human Education. Michel Foucault.

Educação \& Realidade, Porto Alegre, v. 46, n. 3, e107679, 2021. 


\section{Introdução}

A tentativa de sermos contemporâneos ao tempo presente nos confronta com a radicalidade da nossa condição de sujeitos políticos, por sermos seres de linguagem; isto é, o que nos abre para a política é a linguagem. $O$ falatório atual nesse campo (da política) nos leva a ter que enfrentar os modos com que a palavra entra nesse jogo e a vislumbrar possibilidades outras de dizer, que nos abram para novas perspectivas éticas, ou, talvez, nos ajudem a recuperar a condição ontológica de implicação entre ética e política. Afirmamos isto porque, para pensadores como Giorgio Agamben (2009) (o qual endossamos), ser contemporâneo pressupõe, paradoxalmente, não coincidir com o tempo em que se vive, não ser capturado pelas luzes do presente.

É nessa direção que entendemos a ideia de filosofia em Michel Foucault. Para o autor, importa assinalar, há duas grandes tradições na modernidade ocidental no campo da filosofia e ambas têm no filósofo prussiano Immanuel Kant a sua referência central: a filosofia como uma forma de questionamento da legitimidade dos modos históricos de conhecer e a filosofia como prática histórico-crítica (Foucault, 1995). A primeira tem como objeto o problema das condições formais de acesso ao conhecimento e está representada pela lógica e pela epistemologia. A segunda fundou um modo de fazer filosofia que tem na atitude crítica a sua baliza primeira e se realiza em uma prática histórico-filosófica calcada nessa atitude, cuja pergunta central é: “[...] que sou eu, então, que pertenço a esta humanidade, quiçá a esta margem, a este momento, a este instante de humanidade que está sujeito ao poder da verdade em geral, e das verdades em particular?" (Foucault, 1995, p. 12, tradução nossa). A questão radical da filosofia ou do fazer intelectual, nesses termos, está enraizada em um questionamento ontológico sobre o presente e, particularmente, sobre a relação com o presente e suas verdades, sem que isso resulte, como afirmamos com Agamben, em confundir-se com elas.

Ainda não devemos esquecer que esse problema está situado, como bem lembra Butler (2013), no questionamento político que Foucault se coloca, qual seja: como não sermos governados? Como não sermos governados desse modo, por essas leis, por esses sujeitos?, ao que Foucault chamará de uma indocilidade voluntária, evocando, em sentido contrário, a Étienne de La Boétie e sua servidão voluntária, bem como fazendo referência ao seu próprio conceito de Vigiar e punir e a consagrada ideia do poder disciplinar como produtor de corpos dóceis politicamente e produtivos economicamente (Foucault, 1987). A pergunta pelo presente é, assim, constitutivamente política, pondo em relação as noções de crítica e experiência (Lemke, 2017); e o é na medida em que os sujeitos que interpelam o presente o fazem no sentido de assumir uma atitude crítica na relação com o modo de governo ao qual estão sujeitos, protagonizando a criação de outros modos de governo possíveis. Concordamos com o filósofo espanhol Joaquín Fortanet quando afirma que "O lugar desde o qual Foucault parece falar, e reivindica ser 
ouvido talvez pudesse ser esboçado na montagem do conceito de experiência, linguagem e pensamento crítico que se realiza, pela primeira vez, nos seus textos de crítica literária" (Fortanet, 2008, p. 25).

Entendemos que o ponto destacado por Fortanet (2008) é crucial como chave interpretativa para o pensamento tardio de Foucault - produzido no final dos anos 1970 e, principalmente, nos anos 1980 e chamado por Deleuze de ser-consigo (Deleuze, 1992). Dizemos isto porque o problema da resistência não está somente vinculado à oposição ao modo imperante de governo, mas, da mesma forma e de maneira emblemática, à criação de formas outras de vida em comum, formas essas que estejam ancoradas em um compromisso ético com a vida que se vive e inscritas no devir da contingência; portanto, sem qualquer relação com uma lei necessária e universal da história. A vida que se vive e se produz em comum, cuja forma está sempre sendo, nos permite também pensar a formação humana de outro modo, porque pautada basilarmente na ideia de que a constituição da subjetividade tem como alicerce primeiro a dimensão ético-estético-política.

No momento em que o pensador francês se ocupa com as práticas de si produzidas no contexto da Grécia clássica e no helenismo grecoromano, emergirá uma compreensão da subjetividade que, ao ser referenciada na ideia da exemplaridade grega, não tem qualquer referência a-priori para sua produção, mas se realiza na prática permanente de si, a partir da relação com o Outro $^{1}$ e com as coisas, pautada no compromisso ético com a palavra e a vida que se vive. Foucault chama atenção para a ideia de que fazer experiência é esse devir-outro-de-si-mesmo, que põe em jogo as relações entre o saber, o governo e a subjetividade (Foucault, 2016). Essa compreensão comporta, para nós, um potente conjunto de ferramentas que nos permite pensar esse momento de sua obra a partir da perspectiva da experiência e suas implicações políticas e formativas, objeto do presente trabalho. Optamos por dar centralidade aos três primeiros volumes da História da sexualidade. Fazemos essa escolha analítica por entendermos que, nessa obra, o conceito de experiência opera como um vetor do pensamento de Michel Foucault, em particular nas considerações de método.

\section{Notas Iniciais sobre o Conceito de Experiência}

O conceito de experiência tem sido uma categoria balizadora da tradição ocidental de pensamento, em torno do qual tem se constituído um campo semântico. Segundo Jay (2009), esses movimentos estariam pautados por duas grandes premissas, situadas como vetores de produção de sentido em torno da categoria: por um lado, a relação entre experiência e linguagem; por outro, a relação entre experiência, subjetividade e acontecimentalidade ou contingência. O primeiro problema, isto é, questionar em que medida a experiência seria acessível ou não à palavra, é pautado por uma dupla possibilidade, a saber: a) a experiência seria algo a ser realizado, porém não comunicável, sendo, portanto, 
um elemento radicalmente subjetivo; e, por outro lado, b) a experiência seria comunicável, porém em formas singulares de uso da palavra.

Na primeira compreensão, desse modo, observamos a afirmação de que a palavra seria uma barreira que corresponderia a uma necessária perda da experiência, uma vez que ela seria constitutivamente inenarrável. As palavras pressuporiam uma tentativa sempre malsucedida de apreensão do acontecer da experiência. A experiência e a vida, assim entendidas, seriam uma potência situada no plano do acontecer e resistentes a serem capturadas pela palavra, a qual, por sua vez, empreenderia uma e outra vez um vão esforço de apreendê-las.

A segunda posição, da qual aqui nos aproximamos, parte de uma compreensão outra. Ela se afasta da noção de que a ciência é um modo de dizer da experiência, porque a ciência pressupõe exatidão, o que é radicalmente oposto da experiência, porém, admite que a palavra é um médium que precisa de formas singulares de produção para poder dizer e transmiti-la. Inclusive, nesta compreensão, a palavra seria uma dimensão constitutiva da experiência, condição necessária para a sua emergência.

Isso posto, o questionamento aqui é: qual (ou quais) o(s) modo(s) de produção da palavra que comporta(m) a possibilidade de fazer experiência? A linguagem emerge nesta compreensão como uma dimensão ambivalente, tanto de possibilidade e de efetivação do vir-a-ser da experiência (principalmente no âmbito da arte ou, melhor, da relação artística ou artesanal com a palavra), quanto naquela em que a experiência pode estar impossibilitada de ser feita (notadamente na ciência). Em suma, nesta posição, concebe-se que a palavra não comporta uma substância nela própria, independente do seu uso, mas está ontologicamente condicionada pelo modo em que é produzida em diferentes contextos históricos, condição essa que possibilitará ou não fazer experiência.

O segundo problema, a relação entre acontecimento e experiência, nos confronta com a questão de a experiência ser ou não algo da esfera da previsibilidade e da calculabilidade, tanto no que diz respeito ao que pode ser estruturado para provocar o seu acontecer, quanto no que concerne às consequências que o fazer experiência pode ter na produção da subjetividade. Assim, neste caso, também teríamos duas opções. A primeira delas seria pensar a experiência como sendo algo da esfera do acontecer, da contingência na sua radicalidade e que, portanto, não pode ser planejada, tampouco podem ser previstos os seus efeitos na constituição da subjetividade. Nesta perspectiva, a experiência só poderia estar ancorada no movimento subjetivo que não comportasse um conjunto de técnicas ou modos de ação dados a priori e que poderiam possibilitar a sua emergência. Assim, tão somente o indivíduo ou um grupo poderiam operar algo da ordem do radicalmente contingente, via de regra, muito próximo do campo artístico, que não comporta regras a serem seguidas, mas sim elaboradas no próprio processo de produção artística. A segunda opção assume que a experiência seria algo ambivalente, havendo um conjunto de regras e técnicas que, a partir de uma 
relação de compromisso do sujeito com a verdade e a vida, tornariam a experiência possível. Entretanto, tal conjunto não forneceria qualquer previsibilidade do resultado dessa experiência, exatamente por ela pressupor uma abertura radical do sujeito para o vir-a-ser, portanto, sem qualquer modelo identitário definido de forma a-priori, um porto seguro. De todo modo, em ambas as posições, afirma-se a noção de que a experiência é um modo de relação do sujeito com a vida que pressupõe um ser-afetado-do-sujeito no seu ser de sujeito, o que supõe sua transformação, a qual não tem, nunca, um destino traçado, comportando, sempre, um arriscar-se.

Nossa compreensão da obra tardia de Foucault, aqui analisada, vale-se dos dois elementos apontados anteriormente: a) a ideia da palavra como sendo condição de possibilidade de acesso à experiência, porém, a partir de modos singulares de relação com ela; e b) a noção de que a experiência pressupõe uma transformação radical de si mesmo sem qualquer garantia ou porto seguro, mas que comporta um conjunto de regras que a tornam possível.

\section{A Experiência: comentários introdutórios e sua presença na História da Sexualidade}

O conceito de experiência na obra do pensador francês Michel Foucault tem sido um objeto pouco explorado, com uma presença mais expressiva nos estudos sobre literatura (O'Leary, 2008). Não podemos fazer afirmações conclusivas a respeito dos motivos que levam a esse quadro interpretativo da obra (o que tampouco é o objeto deste trabalho), mas pensamos que uma leitura dessa natureza certamente cria limites para a compreensão do projeto teórico foucaultiano. Entendemos, pelo contrário, seguindo nessa postura Fortanet $(2008 ; 2012)$, que a experiência tem um papel central na obra do pensador francês, em particular nos anos 1960, nos escritos dedicados à literatura, mas também desde meados dos anos 1970 até, claramente, os anos 1980 (Jay, 2009), sendo uma categoria balizadora do seu projeto História da sexualidade (Fortanet, 2012). Nesses diferentes momentos, o conceito ganha novos contornos, que vão desde a ideia da experiência de dessubjetivação na escrita literária, passando pelo conceito técnico de correlação entre saberes, normatividade dos comportamentos e constituição dos modos de ser do sujeito e modos de subjetivação, até a experiência como transformação de si (Jay, 2009), sendo esta última a elaboração que aqui discutiremos.

Vale lembrar que, no final da década de 1970, veremos emergir uma nova elaboração do conceito de experiência que comporta elementos centrais para o problema objeto do presente trabalho. O segundo modo de elaboração que Foucault fez da categoria, a partir do final dos anos 70 (de 1976 em diante, mais precisamente), tem como principais espaços de elaboração as entrevistas realizadas com Duccio Trombatori em 1978 (Jay, 2009), os três primeiros volumes da série História da sexualidade (embora os dois últimos sejam mais relevantes em termos 
A Noção de Experiência na História da Sexualidade

de elaboração conceitual) e os cursos ministrados no Collège de France entre 1981 e 1984. Esses materiais, contudo, não apresentam uma compreensão única, senão, pelo menos, em duas construções complementares que guardam um princípio estruturante em comum: a natureza transformadora da experiência.

Tais conceituações se estruturam em torno de dois núcleos de sentido: por um lado, o caráter transformador do ser do sujeito, que não é dado de forma espontânea, mas pela ascese, portanto, por uma estilística da própria existência fruto de um labor constante e metódico, pautado por uma relação de implicação ética do sujeito com a verdade, que sempre acontece na relação com o Outro; e, por outro lado, o conceito de filosofia e o papel do intelectual a ele vinculado, pensado como alguém que tem na filosofia não uma atividade profissional de caráter técnico-instrumental, mas que nela produz um modo de vida, que nunca é de caráter solipsista, mas se realiza a partir de um compromisso ético-político com o mundo presente.

Nas entrevistas concedidas em 1978 ao jornal comunista L'Unità, dirigido por Duccio Trombadori, Foucault mobiliza a categoria para dar forma ao modo como concebe o trabalho intelectual (Foucault, 2009). Importa sublinhar que nesse momento ele já se encontrava em um estágio maduro de sua carreira acadêmica e havia conquistado um lugar de alta relevância no cenário internacional da filosofia e das ciências humanas (tornara-se membro do Collège de France em 1970). Nesse sentido, as entrevistas podem ser consideradas como um espaço de reflexão sobre sua própria trajetória intelectual e a maneira como foi produzida.

Para melhor situar o entendimento do conceito explicitado nesse momento, cabe apresentar algumas elaborações conceituais que Foucault desenvolvera em uma conferência proferida no mesmo ano, intitulada O que é a crítica? - Crítica e Aufklärung. O nosso autor, para situar a sua concepção de filosofia, identifica, como registrado anteriormente, o filósofo prussiano Immanuel Kant como o criador das duas tradições filosóficas hegemônicas da modernidade: a tradição crítica e a tradição calcada na epistemologia e na lógica. A primeira encontra seu lugar de emergência no texto $O$ que é o esclarecimento? e a segunda nas críticas kantianas, sendo, porém, A crítica da razão pura sua principal referência. A primeira está pautada pela pergunta sobre o presente do qual se é contemporâneo e, portanto, a filosofia teria como tarefa primeira fazer uma ontologia do presente; enquanto a segunda se orienta por uma relação formal e de exterioridade com o conhecimento, baseada na preocupação com um percurso lógico na produção da verdade. Foucault inscreve um conjunto de pensadores na primeira tradição, tais como: Max Weber, os intelectuais da Escola de Frankfurt e a ele próprio. Desse modo, ele concebe a tarefa da filosofia como um modo de permanente interrogação do presente que se habita, sem que isso esteja circunscrito ao âmbito exclusivo da filosofia. Além disso, importa sublinhar que, nesse momento, ele se ocupa em definir seu entendimento do que seja a crítica, a qual é concebida como uma atitude, isto é, como uma maneira de questionamento da realidade social que tem como tarefa primeira 
problematizar o modo em que se é governado, avançando em questionamentos sobre os limites e as formas e por quais sujeitos se quer ser governado (Foucault, 1995). Portanto, o problema da crítica comporta para o autor o comprometimento dos envolvidos na problematização e elaboração das relações de poder nas quais se encontram situados. Trata-se de uma questão fundamentalmente política. Pensar significa, portanto, problematizar o presente em que se vive, a partir de uma atitude que é constitutivamente política (Lemke, 2017) e que nos permite conceber a formação humana como um processo sempre em curso, situada no plano do acontecer, porque se pauta pela primariedade da relação e do compromisso ético-político do sujeito com o mundo presente que habita.

Retomando o problema do conceito de experiência a partir das entrevistas concedidas a Trombadori, ao falar dos livros que havia produzido, Foucault afirma que sempre escrevia livros-experiência. Com isso, ele quer apresentar a sua relação com o trabalho intelectual, que, nos moldes do que apresentamos acima, pressupõe o comprometimento ético-político de quem pensa com o objeto da atividade intelectual. Pensar e escrever significam, nesse registro, pensar-se e produzir a si mesmo. Um livro-experiência supõe um tornar-se outro de si, uma transformação do próprio ser do sujeito, no ato da escrita. Para Foucault, só faria sentido escrever um livro se ele se tornasse alguém diferente na relação com o objeto da pesquisa após o processo investigativo (cf. Foucault, 2009). Nessa elaboração, na fase madura da trajetória intelectual do autor, a experiência é considerada como um princípio que norteia o próprio projeto intelectual foucaultiano, portanto, como um conceito chave no desenvolvimento da obra.

Neste momento, vale destacar a centralidade da linguagem no acesso à experiência ou, dito de outro modo, da linguagem articulada com a vida ou, melhor, tornada viva, porque inscrita na vida, como lócus de produção da experiência. Ao conceber o trabalho intelectual desse modo, a experiência também se abre como uma ferramenta conceitual de grande relevo para pensarmos a relação com a linguagem no processo formativo. Para nosso autor, a escrita é um ato de produção de si, que implica antes de qualquer relação com um objeto de conhecimento a ser pensado, um modo singular de relação com a linguagem, que visa superar o (sempre malsucedido) caráter representacional e instrumental da linguagem, para situar o próprio sujeito como ser de linguagem, que se constitui nela.

Em um momento posterior, no contexto de uma entrevista concedida a filósofos norte-americanos na Universidade de Berkley, Foucault recupera a noção de experiência no conceito que ele defende para a filosofia e para o filósofo, dando relação de continuidade ao conceito exposto anteriormente. Ele afirma que "[...] se deve ter uma atitude exigente, prudente, 'experimental'; é preciso a cada instante, passo a passo, confrontar o que se pensa e o que se diz com o que se faz e o que se é" (Foucault, 2004a, p. 219). E, logo depois, arremata: "A chave da atitude política pessoal de um filósofo não deve ser buscada em suas ide- 
ais, como se pudesse delas ser deduzida, mas sim em sua filosofia como modo de vida, em sua vida filosófica, em seu ethos" (Foucault, 2004a, p. 219). Novamente, vemos a indissociabilidade entre experiência e reflexividade; desse modo, experienciar-se é tomar a si próprio como objeto de reflexão e produção, a partir de uma elaboração artesanal do pensamento como modo de vida. A vida que se vive é a caixa de ressonância da verdade e se dá sempre na relação com o Outro.

Outro elemento para o qual queremos chamar a atenção antes de entrar no debate do conceito nos estudos sobre a História da sexualidade é o diagnóstico da modernidade que Michel Foucault realiza na Hermenêutica do Sujeito (Curso de 1981-1982 no Collège de Fránce) e que consideramos fundamental para o nosso argumento. Para o pensador francês, a modernidade seria um período histórico no qual a espiritualidade, nos moldes em que se realizava na antiguidade clássica e, particularmente, na antiguidade greco-latina, não seria mais possível. Portanto, esse movimento de escavação nos territórios da antiguidade se realiza a partir de uma preocupação com o presente, sem pretender, contudo, encontrar qualquer saída, mas escava-se para encontrar outros modos possíveis de produção da subjetividade.

A espiritualidade é concebida por Foucault como um modo de relação do sujeito com a verdade que está marcado por um duplo movimento simétrico: por um lado, o comprometimento ético do sujeito com a verdade enunciada e, por outro, a transformação do ser do sujeito pela relação ética com a verdade, uma etopoiese (Foucault, 2004b). Esse movimento é também conceituado por Foucault como sendo experiência (Foucault, 2004b; 2016). De acordo com o pensador francês, a espiritualidade e a experiência não seriam mais possíveis na modernidade, pois o sujeito moderno é capaz de verdade, porém a verdade da qual é capaz não salva o sujeito (Foucault, 2004b). Assim, o par conceitual resta acessível somente aos sujeitos vinculados ao campo artístico e aos movimentos revolucionários (embora essa tese não seja desenvolvida nos escritos do autor). Além disso, afirma que o cuidado de si e a experiência que lhe é inerente são condições fundamentais para pensar outra política. Vejamos o que ele diz em dois momentos do curso, que são centrais e potentes para o nosso argumento. Na primeira passagem, ao apresentar o problema do curso d'A Hermenêutica do sujeito, afirma que gostaria de colocar o problema da relação entre o dizer-verdadeiro e o governo do sujeito em um contexto anterior ao cristianismo e que, nesse modo de proceder o problema da experiência, seria central. Ainda, ele seria central não só para compreender a questão na antiguidade greco-romana, mas também para problematizar o sujeito ocidental.

Gostaria também de colocá-la [a relação entre dizer-verdadeiro e governo do sujeito] sob a forma e no quadro da constituição de uma relação de si para consigo, a fim de mostrar como se formou nesta relação um certo tipo de experiência de si que, parece-me, é característica da experiência ocidental, da experiência ocidental do sujeito por ele mesmo, mas igualmente da experiência ocidental 
que o sujeito pode ter ou fazer em relação aos outros (Foucault, 2004b, p. 282).

Da passagem acima, interessam-nos dois elementos: o primeiro é a importância atribuída ao problema da experiência nesse momento da obra; já o segundo é o modo como essa relação, pautada pela experiência, pressupõe uma implicação necessária consigo e com o Outro, em termos de um permanente inacabamento, de um permanente vir-a-ser que se elabora em um momento da história, mas diz respeito ao modo de ser do sujeito ocidental enquanto tal. Posteriormente, o autor situa de forma clara a relevância desse aspecto para a política na contemporaneidade. Discorrendo sobre o problema do uso indiscriminado de ideias vinculadas à liberação do eu (o que se revela na enorme produção da literatura da autoajuda, por exemplo) e à pobreza de sentido desses usos, ele situa o potencial crítico da relação para consigo no mundo contemporâneo:

[...] é possível que nestes tantos empenhos para reconstituir uma ética do eu, nesta série de esforços mais ou menos estanques, fixados em si mesmos, neste movimento que nos leva, ao mesmo tempo, a nos referir incessantemente a esta ética do eu sem contudo jamais fornecer-lhe qualquer conteúdo, é possível suspeitar que haja uma certa impossibilidade de constituir hoje uma ética do eu, quando talvez seja esta uma tarefa urgente, fundamental, politicamente indispensável, se for verdade que, afinal, não há outro ponto, primeiro e último, de resistência ao poder político senão na relação de si para consigo (Foucault, 2004b, p. 306).

Vê-se nas palavras acima que a escavação foucaultiana sobre a subjetividade na antiguidade clássica e greco-romana, na qual o problema da experiência é central, se pauta por uma preocupação eminentemente política a partir de uma pergunta (e de um apelo irrecusável) pela criação de outros modos de governo no presente. Certamente que a formação humana é convocada a fazer parte desse processo de constituição do sujeito ético-político, o que nos permite questionarmos o modo de produção da forma escola e do sistema de ensino na modernidade tardia, além do lugar (ou sua impossibilidade) de uma relação de compromisso ético com a palavra.

Depois de percorrer a antessala do conceito de experiência no pensamento foucaultiano, passemos agora à discussão do conceito nos três primeiros volumes da História da Sexualidade.

O projeto teórico de maior envergadura de Michel Foucault é, todos sabemos, a História da sexualidade. A leitura que aqui propomos é que o conceito de experiência é um vetor fundante desse projeto na sua integralidade. Ainda, percebemos que, ao longo do processo de elaboração, o conceito vai se modificando a partir dos terrenos de escavação explorados pelo autor, situando-se entre uma noção técnica e uma ideia, que pressupõe a produção etopoiética da subjetividade, uma estilística da existência. Contudo, entendemos que a experiência concebida 
como produção de si enquanto obra de arte, ou uma etopoiética da subjetividade, comparece e conduz o movimento investigativo em todo o percurso dos três volumes aqui analisados, e não somente nos volumes 2 e 3 desse projeto (principalmente do volume 2), conforme Jay (2009) e Fortanet (2008) sugerem. Entendemos que Foucault se vale da categoria como um vetor orientador de toda a série e que é justamente o deslocamento de sentido da categoria que o leva a operar as modificações que fizera na década de 1980, para criar um horizonte interpretativo do modo de relação de si para consigo, presente, principalmente, na antiguidade clássica e nas escolas do helenismo greco-romano.

\title{
A Experiência n'A Vontade de Saber
}

Para compreender o movimento analítico utilizando a categoria de experiência no primeiro volume - A vontade de saber -, é necessário recorrer ao segundo volume - $O$ uso dos prazeres -, momento no qual Foucault realiza uma retrospectiva de método sobre o projeto. Comentando o seu intuito inicial, o autor nos diz:

\begin{abstract}
Em suma, tratava-se de ver de que maneira, nas sociedades ocidentais modernas, constitui-se uma 'experiência' tal, que os indivíduos são levados a reconhecer-se como sujeitos de uma 'sexualidade' que abre para campos de conhecimentos bastante diversos, e que se articula com um sistema de regras e coerções. O projeto era, portanto, o de uma história da sexualidade enquanto experiência se entendemos por experiência a correlação, numa cultura, entre campos de saber, tipos de normatividade e formas de subjetividade (Foucault, 1984, p. 10, grifo nosso).
\end{abstract}

Na passagem acima, vemos explicitado um conceito de experiência concebido como elemento articulador entre saber, normatividade e subjetividade. $\mathrm{O}$ autor diz que, ao fazer experiência, "[...] os indivíduos são levados a reconhecer-se", isto é, a partir da orientação do outro (que opera como o antigo diretor de consciência), os sujeitos são governados, de modo que passam a assumir como própria a verdade da emergente scientia sexualis e a se pautarem pela normatividade da vida sexual por ela definida, vindo-a-ser, assim, sujeitos assujeitados a esse modo de viver, processo este que se constitui em um agenciamento político da vida (Foucault, 1985a), agenciamento para o qual a emergência do dispositivo da sexualidade foi de fundamental importância, instaurando a ideia de sexo - como objeto; elaboração que teve a sua materialização a partir da produção da mulher histérica, da necessidade de pedagogizar a sexualidade infantil, evitando os riscos do onanismo da criança masturbadora, da patologização psiquiátrica do prazer perverso e da socialização das condutas de procriação, que se expressa no coitus interruptus do casal malthusiano.

Importa assinalar ainda, com relação ao momento inicial do projeto, que, à diferença da tradição pautada pela psicanálise - que, conforme o nosso autor, substancializa o sujeito desejante e historiciza as 
diversas repressões produzidas culturalmente -, ele parte da premissa de historicizar o sujeito de desejo com o objetivo de compreender as condições de emergência que possibilitaram que o homem ocidental fosse levado a se reconhecer como sujeito de desejo. Portanto, trata-se de dessubstancializar a dimensão do ser desejante para situá-la como um problema inscrito no devir da história (Foucault, 1984).

Essa compreensão está pautada por uma categoria cunhada por Foucault no início dos anos 1980: as tecnologias do eu (Foucault, 2008). Preocupado com os modos em que os sujeitos são envolvidos nos processos de subjetivação que os torna o que são, ele propõe que na história ocidental foram desenvolvidas diversas tecnologias de poder que levaram os sujeitos a assumirem para si verdades que emergiram em diversas esferas da vida social, como a religião e a ciência, e a produzirse a partir da implicação e da sujeição a essas verdades, em uma lógica heteronormativa. Essa matriz de subjetivação nasceu com o pastorado cristão, que teve seu lócus privilegiado no cenóbio e sofreu um processo de secularização na ciência moderna. Assim, os sujeitos são levados a se reconhecerem a partir de categorias que diversas instituições modernas fazem circular e que tem como base diversos domínios do saber modernos: na escola, somos levados a nos reconhecermos como alunos, no âmbito das instituições biomédicas, como obesos, hipertensos, diabéticos ou sujeitos normais, aliás, o ideal da biomedicina moderna. Esse conceito, entretanto, também foi aplicado aos estudos do helenismo do cuidado de si, na discussão de processos de subjetivação pautados pela relação entre subjetividade, ética e liberdade. Desse modo, ao introduzir essa categoria, Foucault opera um deslocamento na sua analítica, problematizando o sujeito na produção do seu próprio ser, que é sempre histórico, e serve, portanto, como conceito técnico, tanto para problematizar modos de subjetivação pautados pela heteronormatividade e pela sujeição, como para pensar processos pautados na criação de si como uma estilística da existência.

Apesar de reconhecer a presença central do conceito de experiência nos moldes acima apresentados, entendemos que outra elaboração do conceito já se observa nesse momento, a saber: a noção de experiência como transformação de si. O problema comparece, aparentemente de forma tímida, no primeiro volume, embora já se observe que essa ideia é um vetor importante, diremos fundante, do projeto.

Ao apresentar o objeto do primeiro volume (A vontade de saber), o autor opta por seguir um modo de definição por contraste (como, de resto, é uma prática habitual em Foucault), situando como opostos o que ele entende ser as duas grandes formas de produzir a verdade do sexo. Foucault contrasta uma scientia sexualis com uma ars erotica. A primeira é uma expressão única e exclusiva da ocidentalidade moderna e pautada pelo jogo de verdade da ciência; a segunda era expressão de sociedades antigas que produziram um modo de relação com a sexualidade não dada na ciência, mas em uma maneira artesanal de dar forma à sexualidade. A oposição aqui apresentada entre ciência e arte deve ser destacada, uma vez que a primeira pressupõe regras universais 
e necessárias que se descolam do sujeito para se impor como verdade; ao passo que a segunda pressupõe um comprometer-se do sujeito no objeto (sexualidade), para poder dar uma forma singular a ele e, em assim fazendo, dar-se forma a si mesmo, transformando-se no seu ser de sujeito. Desse modo, no registro da ars erotica, “[...] a verdade é extraída do próprio prazer, encarado como prática e recolhido como experiência" (Foucault, 1985a, p. 57). Se observamos este tripé - verdade-prazer, prática de si e experiência -, podemos ver já desenhado o movimento de produção da subjetividade que será o terreno de escavação do pensador francês nos anos 1980. A relação com a verdade dada no prazer, e não na sua negação, nos coloca em outro lugar para pensar a relação do sujeito com a verdade, que não mais se situa no plano da des-coberta representacional, mas em uma mútua implicação. A prática de si também nos leva a entender que ela - a verdade - está sempre sendo, em um permanente praticar-se, bem como, que dele se produz um outro de si mesmo, a experiência. Além disso, Foucault assinala a importância da relação do mestre com o discípulo e indica que o processo da produção do que, posteriormente, chamaria de uma estilística da existência nos antigos era uma preocupação presente e situada, embora de forma embrionária, nos moldes em que seria desenvolvida na década seguinte. Direcionando a análise para o problema que aqui nos ocupa, se entendermos a ideia de recolher como experiência, no sentido de pensar os efeitos que tal arte pode ter no sujeito (conforme sugerimos acima), chegaremos à compreensão de que esses efeitos se materializam na transfiguração do ser do sujeito, compondo um processo formativo pautado pela autenticidade. Desse modo, a experiência se constitui nos efeitos do pôr-se em jogo na ars erotica. Vejamos o que nos diz o autor:

Os efeitos dessa arte magistral, bem mais generoso do que faria supor a aridez das suas receitas, devem transfigurar aquele sobre quem recaem seus privilégios: domínio absoluto do corpo, gozo excepcional, esquecimento do tempo e dos limites, elixir de longa vida, exílio da morte e suas ameaças (Foucault, 1985a, p. 57).

Vemos assim que o problema da experiência como transformação de si, do ser do sujeito, já está posto como um vetor que orienta a produção do projeto teórico da História da sexualidade desde o seu início, bem como a ideia da ars erotica nos antigos já era uma preocupação presente nesse momento.

Aqui também vale notar que Foucault deixa explicitado que a sexualidade, mesmo na modernidade, nunca pode ser integralmente capturada, sendo que, nesse período histórico e nas próprias instituições que operam a normalização da sexualidade moderna, notadamente a psiquiatria e a psicanálise, há também linhas de fuga, sempre há um resto, a potência da vida sempre resta. Portanto, no período moderno, que é marcado pela ação reguladora e normalizadora das instituições sociais, a sexualidade é também um terreno possível de experimentação. 


\section{O Problema da Experiência n'O uso dos Prazeres}

Consideramos oportuno um preâmbulo em nossa argumentação sobre o conceito de experiência no volume 2 da série, O uso dos prazeres. No verbete Michel Foucault - publicado em 1984 no Dictionnaire des philosophes, mas redigido no início da década de 1980 e, segundo os dados editoriais, parte introdutória da primeira versão desse segundo volume -, o conceito de experiência ganha um lugar central. Assinado sob o pseudônimo Maurice Florence, o texto explicita a relação direta entre subjetividade, experiência e verdade, no seu projeto em curso: “Trata-se, em suma, da história da 'subjetividade', se entendermos essa palavra como a maneira pela qual o sujeito faz a experiência de si mesmo em um jogo de verdade no qual ele se relaciona consigo mesmo" (Foucault, 2004a, p. 236). Importa assinalar que o conceito de experiência é situado como equivalente de relacionar-se consigo mesmo, isto é, assume aqui o lugar do modo específico, singular e histórico no qual o sujeito, ao se relacionar consigo mesmo, se produz. Posteriormente, o autor complementa que a ideia da subjetividade como experiência de si mesmo não se coloca como uma negação absoluta da existência do sujeito, mas demanda "[...] fazer aparecer os processos próprios a uma experiência em que o sujeito e o objeto 'se formam e se transformam'” (Foucault, 2004a, p. 236). Isto é, a noção de experiência pressupõe uma relação reflexiva do sujeito para consigo a partir da relação com o objeto que tem como horizonte a transformação de si, a qual está pautada em um modo singular de relação com a palavra, com a verdade. Ao assumir um compromisso ético-estético-político com a verdade, o modo de formação do sujeito se desloca de uma relação de exterioridade e de cunho instrumental para situar-se como uma prática permanente e reflexiva de si mesmo. Passemos à obra.

O segundo volume da série foi publicado oito anos depois do primeiro, em 1984, momento no qual o autor está inteiramente dedicado ao estudo da antiguidade clássica e, principalmente, das escolas do helenismo grego e romano. Neste caso, não é mais a scientia sexualis o terreno da escavação, mas os aphrodisia, concebidos enquanto substância ética da antiga ars erótica. Ao optar pelo nome aphrodisia e não pela palavra prazeres, realiza-se uma escolha importante pela não transitividade dos conceitos; embora trate-se de uma obra sobre a sexualidade, os objetos da sexualidade grega não podem ser subsumidos àqueles da ciência sexual moderna; o arcabouço lexical da ars erótica antiga não permite uma relação transitiva com os conceitos da moderna scientia sexualis.

Foucault apresenta a singularidade do estudo empreendido sobre a sexualidade, os deslocamentos metodológicos operados no percurso e a reelaboração do objeto inicial, e afirma que optou por “[...] estudar os jogos de verdade na relação de si para si e a constituição de si mesmo como sujeito, tomando como espaço de referência e campo de investigação aquilo que poderia chamar-se de 'história do homem do desejo'” (Foucault, 1984, p. 11). Nesse deslocamento, o próprio conceito de ex- 
A Noção de Experiência na História da Sexualidade

periência sofre também alterações, na medida em que abre um espaço para a reflexividade da relação de si para consigo, porque deve dar a pensar e se pensar, situando-se nos jogos do verdadeiro e do falso e não no âmbito do conhecimento. Vejamos:

Uma história que não seria aquela do que poderia haver de verdadeiro nos conhecimentos, mas uma análise dos 'jogos de verdade', dos jogos entre o verdadeiro e o falso através dos quais o ser se constitui historicamente como experiência, isto é, como podendo e devendo ser pensado (Foucault, 1984, p. 12, grifo nosso).

Vemos na passagem acima um postulado teórico central para o trabalho foucaultiano, pelo menos desde o final dos anos 1970, que se constitui na tríade do ser, da experiência e do pensamento (e o jogo entre o verdadeiro e o falso que lhe é inerente). Desse modo, é expressa a ideia de uma ontologia histórica, na qual o ser se dá na experiência, esta concebida como as diversas formas, sempre contingentes (porque situadas no plano da historicidade) do pensar-se do sujeito. Evidentemente que a linguagem ocupa um lugar central nessa elaboração, na medida em que o pensar se dá na linguagem, morada dos jogos de verdade. Esse movimento o levará a ter como problema do projeto: "Através de quais jogos de verdade o ser humano se reconheceu como homem de desejo?" (Foucault, 1984, p. 12).

O conceito de experiência afirmado neste momento por Foucault, entretanto, tem dupla face e comporta uma ambivalência que é preciso apontar. Ao passo que define o objeto a partir da relação entre o ser, a experiência e os jogos de verdade, também se ocupa em definir a condição do pensador e o conceito de filosofia com base na noção de experiência. Recuperando as ideias já apresentadas desde o final da década de 1970, anteriormente expostas neste trabalho, o autor reafirma que a única curiosidade de valor é aquela que permite a quem pensa "[...] separar-se de si mesmo" (Foucault, 1984, p. 13), ao passo que também, ao se perguntar sobre o conceito de filosofia, afirma em tom interrogativo: "Mas o que é filosofar hoje em dia - quero dizer a atividade filosófica senão o trabalho crítico do pensamento sobre o próprio pensamento?" (Foucault, 1984, p. 13). Portanto, ao assumir esse conceito, o autor se compromete no que pensa e faz, envolve seu modo de pensar e viver no próprio trabalho intelectual, não podendo ser este concebido como algo com o qual se mantém uma relação de caráter técnico-instrumental.

A aparição deste conceito certamente está vinculada à aproximação do pensador francês da antiguidade clássica e greco-latina, já em curso na década de 1970. É bom lembrar que um dos principais autores nos quais Foucault se referencia é Pierre Hadot, cujos estudos sobre a antiguidade e, em particular, sobre as escolas do helenismo foram de fundamental importância no projeto intelectual foucaultiano dos anos 1980. Hadot recuperou a ideia de filosofia como modo de vida nos antigos e seus estudos vieram à lume já desde o início dos anos 1970, sendo que o seu trabalho Exercícios espirituais, que é referenciado por Foucault, data de 1977. Já desde essa década, o problema de revisar o 
conceito de filosofia parece ser uma preocupação presente na obra foucaultiana. Retomando a tradição moderna do ensaio e situando-se na esteira do conceito de filosofia como modo de vida, ele afirma

\begin{abstract}
O 'ensaio' - que é necessário entender como experiência modificadora de si no jogo da verdade, e não como apropriação simplificadora de outrem para fins de comunicação - é o corpo vivo da filosofia, se, pelo menos, ela for ainda hoje o que era outrora, ou seja, uma 'ascese', um exercício de si, no pensamento (Foucault, 1984, p. 13, grifo nosso).
\end{abstract}

De novo vemos reafirmado, em paralelo, o lugar da experiência como modificação de si no e pelo pensamento, nos moldes que havíamos observado anteriormente. Isto é, para Foucault, pensar pressupõe, em primeiro lugar, uma prática crítica sobre si mesmo que vise a autotransformação daquele que pensa, um exercício de si sobre si. A linguagem é uma dobra e um dobrar-se sobre si. Portanto, entendemos o conceito de experiência como uma fita de Möebius, que comporta, neste momento da obra foucaultiana, uma dupla face, inseparável: a produção do sujeito moral como experiência e a autotransformação daquele que pensa. Concebemos esse princípio como sendo de capital importância para pensarmos a formação humana, porque nos abre para um processo sempre em curso, inacabado e contingente.

Vale o alerta de que o pensador francês opera com a ideia de que moral não é a imposição de um código socialmente dado sobre o indivíduo, mas a relação singular que o sujeito estabelece com o conjunto normativo que está posto na ordem social à qual pertence. Foucault nos diz:

\begin{abstract}
[...] por 'moral' entende-se igualmente o comportamento real dos indivíduos em relação às regras e valores que lhes são propostos: designa-se, assim, a maneira pela qual eles se submetem mais ou menos completamente a um princípio de conduta; pela qual eles obedecem ou resistem a uma interdição ou a uma prescrição; pela qual eles respeitam ou negligenciam um conjunto de valores; o estudo desse aspecto da moral deve determinar de que maneira, e com que margens de variação ou de transgressão, os indivíduos ou os grupos se conduzem em referência a um sistema prescritivo que é explicita ou implicitamente dado em sua cultura, e do qual eles têm uma consciência mais ou menos clara (Foucault, 1984, p. 26).
\end{abstract}

Portanto, o conceito de moral defendido se apresenta como sendo de caráter ambivalente, podendo levar à sujeição, mas também à resistência, uma vez que implica o sujeito e/ou o grupo como instâncias que não somente sofrem o código, mas precisam in-corporar (tornar corpo) o código e, desse modo, existe margem para a crítica. De forma complementar a essa definição, como que constituindo um par conceitual, nosso autor vai propor a existência histórica de dois tipos de morais: as morais orientadas para o código e aquelas orientadas para a ética. As pri- 
meiras se pautam por um rigoroso e exaustivo detalhamento dos códigos de conduta a serem observados, por um ordenamento institucional que cumpre o papel de controle e inculcador do código, bem como de aplicar as sanções devidas, caso ele não seja seguido na sua integralidade. São códigos juridificados e assentados nas instituições sociais, que garantem a sua introjeção e privilegiam a dimensão estrutural da ordem social. Evidentemente este tipo de código limita a margem de ação para a constituição de si como sujeito moral e, portanto, o espaço para se realizar a experiência (nos moldes que estamos expondo) resta, evidentemente, quase nulo. Suspeitamos que, para Foucault, a sociedade ocidental moderna é um exemplo claro de ordem social na qual impera este tipo de códigos. Já as morais orientadas para a ética estão centradas na dimensão das “[...] formas de subjetivação e das práticas de si” (Foucault, 1984, p. 30). Neste caso, a codificação não é exaustiva, mas está centrada por um conjunto de regras de existência, a partir das quais o sujeito elabora uma relação singular de si para consigo e com o Outro. Seguindo o autor, “[...] a ênfase é dada, então, às formas das relações consigo, aos procedimentos e às técnicas pelas quais são elaboradas, aos exercícios pelos quais o próprio sujeito se dá como objeto a conhecer, e às práticas que permitam transformar o seu próprio modo de ser" (Foucault, 1984, p. 30, grifo nosso). Vemos que neste tipo de moral o problema está centrado na produção do sujeito como sujeito moral, para o qual fazer experiência é condição necessária. A interpretação foucaultiana é a de que em algumas escolas da antiguidade clássica e do helenismo greco-romano este segundo tipo de moral teria sido predominante. Por fim, cabe ressaltar que ambos os tipos de moral não são excludentes, podendo se contrapor, coexistir e, inclusive, compor. Não seria correto, portanto, confundir os diferentes regimes de moralidade com ordens sociais, mas pensar que em diferentes ordens sociais coexistem diferentes regimes morais, embora com diferenças substantivas na sua importância e na sua localização nessas mesmas ordens sociais ${ }^{2}$.

Certamente, não se trata, neste momento (tampouco foi a intenção do autor), de usar a experiência das escolas do helenismo grecoromano como um horizonte para referenciar a formação humana no presente. Contudo, é uma elaboração de relevo para nos convidar a pensar que a subjetividade é abertura para outros modos de subjetivação. Porém, tal abertura não está dada, mas precisa ser potencializada pelas condições sociais e institucionais específicas nas quais a produção da subjetividade está sempre a emergir, neste caso, calcada na ideia de uma produção singular, porque estética, etopoiética, de relação com as regras de existência.

\section{A Experiência n'O cuidado de Si}

A principal diferença entre os volumes dois e três da História da sexualidade é o período histórico em que eles se localizam. Enquanto $O$ uso dos prazeres está situado no período clássico da Grécia, O cuidado de si se ocupa com os dois primeiros séculos do Império Romano, porém 
abordando temáticas análogas. Contudo, também há diferentes acentos metodológicos, porque no segundo volume se realiza uma apresentação genealógica do projeto e no terceiro se situa o conceito de cuidado de si de forma detalhada e precisa, com o tradicional rigor conceitual dos livros foucaultianos. Justamente, é nessa elaboração do conceito que o problema da experiência comparece no terceiro volume da série e retoma o debate acerca da relação de si para consigo que pressupõe a transformação de si mesmo.

Ao discutir o conceito de individualismo, o nosso autor apresenta três elaborações conceituais: como valor absoluto do indivíduo, como valorização da vida privada e como intensidade das relações consigo. Esse último é o que importa a Foucault, definindo-o como as "[...] formas nas quais se é chamado a se tomar a si próprio como objeto de conhecimento e campo de ação para transformar-se, corrigir-se, purificar-se, e promover a própria salvação" (Foucault, 1985b, p. 48). Na análise foucaultiana, em alguns setores ou instituições da antiguidade clássica e greco-latina, o que se destaca é uma relação intensa de si para consigo, que tem como horizonte a transformação do ser do sujeito, a sua salvação. Essa salvação deve ser entendida a partir da noção de exemplaridade, isto é, da imortalização do sujeito a partir da produção de uma existência de tal modo virtuosa que se inscreva na memória histórica da pólis.

Devemos sublinhar, ainda, que esse modo de elaboração de uma estilística da existência não pode de modo algum ser confundido com um recuo na individualidade sem qualquer compromisso com a vida social e política; portanto, não pode ser entendido como uma enclausuramento solipsista do indivíduo. A produção da subjetividade demanda um Outro como condição de possibilidade; a formação de si implica uma relação de alguém que já sabe cuidar de si, que ajuda um outro a aprender a cuidar de si, relação esta que, com o decorrer do tempo, pode transmutar-se reciprocamente. Nas seguintes palavras, encontramos uma precisa apresentação dessa ideia:

Quando, no exercício do cuidado de si, faz-se apelo a um outro, o qual adivinha-se que possui aptidão para dirigir e para aconselhar, faz-se uso de um direito; e é um dever que se realiza quando se proporciona ajuda a um outro ou quando se recebe com gratidão as lições que ele pode dar (Foucault, 1985b, p. 58) ${ }^{3}$.

A experiência do cuidado de si tem como objeto a produção de uma ética do domínio. Contudo, importa assinalar que essa ética não está calcada exclusivamente na interdição, pelo contrário, o seu alicerce é o prazer, o aprazer-se de si mesmo. O estado que se objetiva alcançar não é concebido como uma relação de repressão do corpo ou uma possessão racional sobre as paixões, sem mais. O que está em jogo é uma lenta elaboração racional da relação entre corpo e alma, que torne possível o governo de si mesmo pautado no prazer que se tem de si. Sem deixar de haver uma primariedade da alma como objeto do cuidado, o corpo ganha um estatuto privilegiado no cuidado de si, estabelecen- 
do com a alma uma relação de intercâmbio. Dessa maneira, a ética do domínio pressupõe uma estilística da existência que tome a si mesmo como objeto de cuidado, mas tendo o prazer como objeto de elaboração:

\begin{abstract}
[...] a experiência de si que se forma nessa posse [de si mesmo] não é simplesmente uma força dominada, ou de uma soberania exercida sobre uma força prestes a se revoltar; é a de um prazer que se tem consigo mesmo. Alguém que conseguiu, finalmente, ter acesso a si próprio, é, para si, um objeto de prazer. Não somente contenta-se com o que se é e aceita-se limitar-se a isso, como também 'aprazerse' consigo mesmo (Foucault, 1985b, p. 70-71).
\end{abstract}

Detemo-nos um instante na passagem anterior para indicar a relação fundante entre experiência e reflexividade. Contudo, a reflexividade não pressupõe uma relação racional e de exterioridade com um objeto de conhecimento, mas uma relação reflexiva para consigo, pautada por uma racionalidade de cunho ético-estético, um modo de ser da razão que comporte o prazer como matéria de elaboração, como substância ética. Entendemos que aqui se abre um excelente problema para pensarmos o modo de Foucault relacionar-se com essa questão, porque, assim entendemos, não se trata de negá-la (a razão), mas de pensá-la para além do sujeito da consciência, situando o prazer de si mesmo como a substância a partir da qual ela se constitui. Prazer que nunca pode ser pensado em moldes solipsistas (porque então não haveria prazer, já que este pressupõe um Outro), mas ao qual se chega pela laboriosa moldagem de si, que resulta no domínio de si, e que se realiza na relação com o Outro, uma racionalidade fundada na dimensão éticoestética, que está sempre sendo, em sua radical contingência e historicidade.

Ao pensarmos na formação humana com base nessa ideia, concebemos que a aposta foucaultiana nos apresenta um rico horizonte para refletirmos sobre uma outra racionalidade no processo de subjetivação, porque fundada em uma dimensão ético-estética. Compreendemos esse movimento, enquanto tal, como uma experiência, que possibilita que outros elementos entrem em jogo ao concebermos o processo formativo, dos quais queremos destacar um em particular: a relação entre corpo, prazer e pensamento. Entendemos essa tríade como uma pista para um vir-a-ser possível de uma concepção formativa radicalmente diferente daquela que impera no sistema de ensino contemporâneo. $\mathrm{O}$ prazer de si, como já sublinhado, não implica uma entrega desenfreada aos deleites de corpo, mas uma lenta elaboração do domínio de si, que resulta da indissociabilidade entre o pensar e a condição corpórea do humano, que torna o pensar radicalmente imanente e contingente, e, portanto, histórico. Além disso, convida-nos a entender o pensamento não como a captura e a apreensão de um objeto cognoscível, mas como um modo de presença do sujeito na relação consigo, e de abertura ao Outro e ao mundo. 


\section{Considerações Finais}

Acompanhar o percurso da experiência no terceiro domínio da obra foucaultiana nos permite vislumbrar a potência da categoria experiência no projeto intelectual e de vida de Michel Foucault. Desse modo, longe de ser um conceito periférico ou marginal, entendemos que o conceito de experiência ganha centralidade em tal projeto, bem como que ele é umbilicalmente relacionado ao problema da política.

É relevante sublinhar que a questão da experiência está fortemente ligada à criação de um modo singular de relação com a vida. Neste registro, a subjetividade somente pode emergir, pode vir-a-ser, a partir de um trabalho minucioso na relação de si para consigo, no qual as palavras e as regras de existência são selecionadas e incorporadas de maneira artesanal, para compor um modo de vida pautado pela excelência e pela exemplaridade, para produzir a própria vida como obra de arte. Cumpre destacar, ainda, que o movimento analítico realizado por Foucault com relação aos antigos não foi somente um olhar longínquo, exterior, mas também envolveu a transformação de quem pensa no ato da escrita: fazer experiência de si. Lembramos, todavia, que esse ato de escrita e de transformação de si, esse ato que a experiência pressupõe, é constitutivamente político e não uma fuga na interioridade, uma capitulação diante do mundo social, do mundo comum.

Entendemos que o projeto da História da sexualidade foi orientado pelo vetor da experiência e que o conceito foi sendo aberto e multifacetado ao longo do movimento investigativo. Já desde o início, n'A vontade de saber, se observa a ideia, ainda em estado germinal, da experiência como um modo singular de relação do sujeito consigo mesmo, que permite transcender a dimensão do assujeitamento da moderna scientia sexualis. Nos volumes seguintes, O uso dos prazeres e O cuidado de si, se consolida e se adensa a ideia de experiência como transformação de si, que se realiza em uma laboriosa e artesanal prática permanente de si, a partir de uma relação singular com as palavras e as regras morais.

O problema da experiência no percurso que fizemos nos possibilita novas aberturas para pensarmos a formação humana. Abre-nos um outro horizonte para pensar a relação do sujeito com a linguagem, relação na qual o sujeito se dá a si mesmo e se produz. Ao mesmo tempo que ser um sujeito de linguagem nos coloca na condição da abertura para o Outro, convida-nos a pensar a linguagem e a experiência como elementos que compõem a formação ético-estética-política do sujeito. A linguagem e a experiência, assim concebidas, nos confrontam com o desafio de deslocar o problema da racionalidade, para ancorá-lo na vida que se vive sempre com-o-Outro, e que se encontra enraizada e materializada no corpo em sua radical imanência, contingência e historicidade.

A experiência de si pressupõe uma volta sobre si, um distanciar-se para voltar a si. Experienciar-se é voltar a si sempre de outro modo, porque o si já se encontra afetado pelas regras de existência que se incorpo-

Educação \& Realidade, Porto Alegre, v. 46, n. 3, e107679, 2021. 
raram, que se fizeram corpo; é ter-se sempre de outro modo, porque a ideia que atravessa o corpo o transforma em múltiplos devires. Prazeres de si mesmo ${ }^{4}$.

Recebido em 20 de setembro de 2020 Aprovado em 12 de março de 2021

\section{Notas}

1 Optamos por escrever a palavra Outro neste trabalho com maiúscula, para nos referirmos às relações intersubjetivas que se constituem a partir da produção da diferença em sua radicalidade. O Outro é assim concebido desde a perspectiva da Outredade. Desse modo, o Outro é aquele ao qual o sujeito se refere e com o qual o sujeito se relaciona, sem subsumi-lo à condição de uma subjetividade normalizada. A noção de Outredade tem sua referência no conceito anglófono de Otherness.

2 Interessa salientar a respeito d'O uso dos prazeres que a estrutura do livro e os capítulos que o compõem se organizam a partir dos quatro eixos da experiência da sexualidade, conforme a análise que o nosso autor fizera dos aphrodisia na antiguidade, a saber: a relação com o corpo, a relação com a esposa, a relação com os rapazes e a relação com a verdade (Foucault, 1984, p. 31). Podemos afirmar, portanto, que a obra na sua integralidade tem na noção de experiência o seu ponto de ancoragem e estruturação.

3 Importa assinalar que Foucault fará referência ao conceito de psicagogia, contrapondo-o ao de pedagogia, para pensar a formação humana no contexto da antiguidade greco-latina. Contudo, esse debate foge do escopo do presente ensaio (cf. Freitas, 2013).

4 Educação \& Realidade informa que a publicação deste estudo foi em parte financiada pela Coordenação de Aperfeiçoamento de Pessoal de Nível Superior - Brasil (CAPES) - Código de Financiamento 001.

\section{Referências}

AGAMBEN, Giorgio. O Que É o Contemporâneo? e outros ensaios. Chapecó: Argos, 2009.

BUTLER, Judith. O Que É a Crítica? Um ensaio sobre a virtude de Foucault. Cadernos de Ética e Filosofia Política, São Paulo, n. 22, v. 1, p. 159-179, 2013.

DELEUZE, Gilles. Conversações. São Paulo: Editora 34, 1992.

FORTANET, Joaquín. Leer a Foucault. Una crítica de la experiencia. Daimon Revista Internacional de Filosofía, Murcia, n. 43, p. 15-32, 2008.

FORTANET. Experiencia, Ética y Poder en la Obra de Michel Foucault. Oxímora - Revista Internacional de Ética y Política, Barcelona, n. 1, p. 96-114, 2012.

FOUCAULT, Michel. História da sexualidade II: o uso dos prazeres. Rio de Janeiro: Graal, 1984.

FOUCAULT, Michel. História da Sexualidade I: a vontade de saber. Rio de Janeiro: Graal, 1985a.

FOUCAULT, Michel. História da Sexualidade III: o cuidado de si. Rio de Janeiro: Graal, 1985b. 
FOUCAULT, Michel. Vigiar e Punir - história da violência nas prisões. Rio de Janeiro: Vozes, 1987

FOUCAULT, Michel. ¿Qué es la Crítica? crítica y aufklärung. Daimon - Revista Internacional de Filosofia, Murcia, n. 11, p. 5-25, 1995.

FOUCAULT, Michel. Ética, Sexualidade, Política - ditos e escritos. Vol. 5. Rio de Janeiro: Forense Universitária, 2004a.

FOUCAULT, Michel. A Hermenêutica do Sujeito. São Paulo: Martins Fontes, 2004b

FOUCAULT, Michel. Tecnologías del Yo. Buenos Aires: Paidós, 2008.

FOUCAULT, Michel. El Yo Minimalista y Otras Conversaciones. Buenos Aires: La Marca Editora, 2009.

FOUCAULT, Michel. Subjetividade e Verdade: curso no Collège de France (19801981). São Paulo: Martins Fontes, 2016.

FREITAS, Alexandre Simão de. A Parresía Pedagógica de Foucault e o Êthos da Educação como Psicagogia. Revista Brasileira de Educação, Rio de Janeiro, v. 18, n. 53, p. 325-338, jan. 2013.

JAY, Martin. Cantos de la Experiencia - variaciones modernas sobre un tema universal. Buenos Aires: Paidós, 2009.

LEMKE, Thomas. Foucault, Governamentalidade e Crítica. São Paulo: Editora Politeia, 2017.

O'LEARY, Timothy. Foucault, Experience, Literature. Foucault Studies, n. 5, p. 5-25, 2008.

Santiago Pich possui graduação em Educação Física pelo Instituto Del Profesorado en Educación Física e mestrado em Ciência do Movimento Humano pela Universidade Federal de Santa Maria. Doutorado no Programa de Pós-Graduação Interdisciplinar em Ciências Humanas da Universidade Federal de Santa Catarina (UFSC). Pós-Doutorado na Universidade de Barcelona (UB). É Professor do EED/CED/UFSC. Atua com pesquisas que discutem a relação entre linguagem, corpo e formação humana.

ORCID: https://orcid.org/0000-0002-8064-1320

E-mail: santiagopich@gmail.com

Editora-Responsável: Fabiana de Amorim Marcello

Este é um artigo de acesso aberto distribuído sob os termos de uma Licença Creative Commons Atribuição 4.0 Internacional. Disponível em: <http:// creativecommons.org/licenses/by/4.0>. 